\title{
Air pollution caused by war activity
}

\author{
C. Protopsaltis \\ Chamber of Technology, Greece
}

\begin{abstract}
Air pollution depends on the controls which can be applied on its type and extent. Pollution caused by industrial processes and the unavoidable needs for everyday living can be controlled adequately by available and new technology and by the effort of the individuals. It is the pollution caused by war activity, during development and testing of hardware, weapon systems and procedures, also during war operations and subsequent reconstruction, which need serious consideration to avoid gradual deterioration of the environment and in particular the quality and temperature of the air. Apart from the chemicals involved in war activity, the uncontrolled discharge of large quantities of heat should be considered seriously since it appears to accumulate, influencing the streamlines of the air flow and its distribution and therefore the climate of the planet.

Keywords: war activity pollution, chemicals in war, development of war hardware, testing of weapons and war hardware, pollution due to reconstruction, chemical pollution, firestorm and air quality, heat due to war activity, war activity and planet's climate.
\end{abstract}

\section{Introduction}

Pollution of the air must concern every human. Aristotle regarded air as one of the five important elements for life on the planet.

A series of conferences have taken place through the years on the subject of pollution of the environment and in particular, pollution of the air, concerned primarily with the need for formal control. A conference concluded recently, the UN Conference on the Human Environment, where air pollution featured as an important topic. Agreements reached at each conference are recorded with the issue of declarations.

In the declarations of the 1972 Stockholm Conference there was no mention of the relevance of war in the pollution of the environment, although in 
Principle 6 there is reference to '....the release of heat to such quantities or concentrations so as to exceed the capacity of the environment....". The declarations of the 1992 Rio Conference made reference, in Principle 24, to war '...... which is inherently destructive of sustainable development' and that 'states shall therefore respect International Law, providing protection for the environment in times of armed conflict ......' It appears that there is concern, absence of specific details but no effective action.

A number of topics will be presented and discussed in this conference. It is proposed, by this paper, that it must include one more topic, which appears to be often neglected, the topic of contribution of war activity to the pollution of the air, and in particular, the significance of the release of large quantities of heat in the atmosphere.

An attempt is being made, by presenting this paper, to refer in some detail to the many ways in which war activity, particularly since the beginning of the $20^{\text {th }}$ Century, has been responsible for the pollution of the air we breathe, before, during and for some time after the war activity ended, and for the increase of its temperature.

\section{Air pollution during the development and testing stages}

The impact of war activity on the environment, particularly on air pollution, starts with the development and testing of all aspects related to military weapons, hardware and armament, and the necessary training in its use.

Between 1945 and 2009 a number of nations undertook development of nuclear weapons. It involved more than 2000 tests within a period of 64 years and cannot be doubted that the air quality was heavily affected both by the chemicals which were released in the atmosphere and more importantly by the heat which was added to the planet's system and must have influenced the streamlines of natural air flows over land and sea, and also impacted on the planet's flora and fauna, and the humans.

Artillery shells and bombs, small, large and very large, also chemical weapons, are constantly being developed and tested while ignoring the restrictions which were placed on them, by international agreement, to ensure the protection of the environment and the quality of the air.

\section{Wars through the years to the present}

Planet earth has a long history of wars, which have 'evolved' spectacularly through the centuries. In the past, a warrior would leave his home in the morning to go and fight. He knew that unless he was killed or incapacitated, he would be re-united with his people the same evening. This, however, changed through the years, with some wars often lasting for decades.

The tools of war are constantly changing, going through stages of development, although the backdrop of the wars did not change.

The warrior of the past depended on the forest for the harvesting of wood to make bows and arrows. The forest bore the brunt of the war, with very little 
impact on the environment's air quality, although fire was eventually added to the arsenal of weapons and this must have impacted on the environment of the day. Undoubtedly, the effects of fire caused by natural phenomena, such as lightning strikes and volcanic eruptions, would have been then more serious.

Today, war is so different. The weapons are varied and versatile and can have multiple effects, particularly on the environment and the quality of air humans breathe, before, during and after every such event, apart from destroying the opponents' life. It is possible now to watch events as they happen, although, very little, if anything, is said while things are happening, about the expected impact on the individuals, those who were in the middle of operations, the noncombatant population and those who in the future will suffer from the pollution of the air caused.

\section{Weapons used in modern warfare}

When a bullet is fired, one experiences noise and witnesses eventual impact. However, that bullet will more likely release in the atmosphere tiny particles of metal, including, for instance lead. These particles are very light and can eventually settle on any surface or can travel with the air with which they have been mixed and become a permanent component of the air mass. In modern day war, bullets are fired in the millions. Therefore their effect on the air quality would be very serious.

Moving up the scale, we have hand grenades, small bombs, cluster bombs, large bombs and very large bombs all of which must add to the unwanted particles in the air.

Since the beginning of the $20^{\text {th }}$ century the use of bombs and shells intensified, culminating in what is now referred to as 'carpet bombing' or 'strategic bombing', a feature of war which appeared since just before the WW2.

Fire always featured prominently in war through the years and seems to have been perfected sufficiently during WW2. Incendiary bombs were developed and used extensively in carpet bombing air raids.

In 1937, during the Spanish Civil War, the Spanish Air Force and its allies bombed the city of Guernica continuously over 48 hours, creating a firestorm, a condition in which the intensity of fire creates and sustains its own wind system. In this type of situation, apart from the destruction of human life, a condition exists similar to that in an industrial incinerator. However, in an industrial incinerator anything and everything is burned under controlled conditions, by law, to avoid air pollution. In Guernica, everything that stood in the path of the fire was incinerated without means of protection against pollution of the air. Some of the pollution may be still present to-day. It could become air-borne and migrate continuously, depending on weather conditions..

Similar firestorms were created during WW2 in a number of cities, in Germany, Poland, and in Japan. The impact of such war activity on the environment of the areas affected directly, and those which happened to be in the path of the present air currents and those in the future, was obviously not considered or even ignored at the time. 
It is essential to consider the extent of heat produced during firestorms, which is very intense and concentrated. The heat dissipates in the air, locally, but remains, to a large extent, captive within the planet's atmosphere, adding to the already existing heat.

While the conflict of WW2 was continuing, nuclear bombs were being developed and tested in the atmosphere between 1945 and 2009. Apart from the deadly chemicals which are released by these tests, there is also the release of intense heat, which seems to be ignored when considering the contribution of such events to air pollution.. Although compensation was paid to some of those whose health was affected, it is impossible to compensate the environment and the air quality for the damage caused, which will persist for some time.

Adding to the pollution and release of heat is the extensive use of aircraft. In one case, 4,000 sorties a day were necessary to deliver the destructive power against the enemy and this persisted over a whole month. Undoubtedly, this must have some influence on the air quality because of the aircraft emissions and the concentration of disturbance of the air currents, affecting the streamlines of the natural flow. To this should be added the heat produced by the burning of the fuel

It is easy to forget that after the destruction of property and infrastructure during the war activity, it eventually becomes necessary to re-construct. This is a process which requires time and involves high cost. Unfortunately, it also creates additional pollution which is produced eventually by the manufacture and re-construction processes.

\section{Pollution caused by chemical weapons}

Chemical weapons were used by almost all the participants in WW1. The substances used were intended to irritate and disable although they caused a lot of injuries and deaths.

The use of these weapons continued in the small wars and conflicts that took place up to WW2, ignoring the Geneva Gas Protocol which was signed in 1925.

Gas weapons were not used in WW2, although both sides of the conflict were prepared with adequate stocks of chemical weapons. As it was proven eventually, it was hardly necessary to produce and deliver these weapons in WW2 since, ironically, the same result was obtained by the use of carpet bombings which resulted in the firestorms and targeted, unfortunately, mostly the civilian populations. Nevertheless, these stocks of chemicals will still pollute while they are being destroyed or if fall in the wrong hands.

Extensive use of incendiary bombs was made in producing the firestorms. The bombs were filled with fire producing chemicals such as napalm and white phosphorus. Chemical weapons were also used recently in the Iraq-Iran war and again in Iraq.

The effects of the by-products of intense fire on the air quality were made obvious in the World Trade Centre incident where pollution from the burning of the buildings and their contents included toxic metals, asbestos, dioxins, 
Polycyclic Aromatic Hydrocarbons, Polychlorinated Biphenyls, and hydrochloric acid.

Other forms of chemical warfare included the development of particular dioxins such as agent-orange which was used in the war in Vietnam. It was used as a defoliant and was delivered by plane, as a tool of war and not necessarily applied as a weapon. However, it proved very effective as a pollutant.

\section{The effect of heat added to the air}

Let us consider the simplest form of adding heat to the air. Striking a match will add minutely to the air pollution. The amount of pollution will be very small and it will soon disperse so that it may not be noticed. The air will be charged, at the same time, with a very small amount of heat which will be also dispersed and it will not be noticeable. What must be emphasised, however, is that this minute amount of heat cannot be ignored since it is immediately added to the environment. It will soon disperse and be forgotten. It is difficult, however, to forget and ignore what is added to the atmosphere when a shell is exploded or a bomb, a very large bomb or an atomic bomb. The heat produced by such explosions is very large and significant. What if the explosion is not an isolated event but instead, one of many, as those which took place during WW1 in the Western Front, continuous over many days or months? This type of event cannot be ignored or discounted. What if it is a situation such as the one created in Guernica, Spain, which produced a firestorm; also the firestorms that followed in WW2 in Hamburg, Dresden, Warsaw, Tokyo and many other European and Japanese cities.

Such extreme events are significant and serious because they must add a large amount of heat to that which already exists in the air.

In the past these events were very infrequent and not as serious. Reference to war activity before the beginning of the twentieth century would indicate that it was not as intensive or concentrated as that which was experienced during conflicts in the twentieth century and beyond.

The most significant war event at the beginning of the twentieth century was WW1. It lasted more than four years, during which a very large fire power was unleashed from both sides, concentrated in Europe. It heralded the introduction of more destructive weapons and extensive use of chemical weapons. The largest part of the heat produced during this conflict did not escape from the planet. It gradually dispersed and was mixed with the air in the atmosphere, thus influencing the already existing level of heat in the air. The Spanish civil war and the war in Ethiopia followed and almost immediately followed by WW2, which was concentrated initially in Europe, then in Asia and the Pacific. There were land battles, sea battles, destruction of transport ships, ait battles and bombings, flying bombs and ballistic missiles, and eventually atomic bombs.

Between 1939 and 1945 there was intense fighting in most of Europe, the Middle East, North Africa, the Pacific islands and Japan.

About 25 cities in Europe were $40 \%$ to $80 \%$ destroyed, and about 55 cities in Japan had the same fate. 
Estimates quote about 3,000,000 tons of bombs dropped on Europe. There were 2,500,000 fighter sorties, 55,000 enemy planes destroyed, 20,000 bomber planes lost, also 20,000 fighter planes lost, apart from other losses of various types of armament. Obviously, a very large amount of heat is represented by these quantities, if included is the heat resulting from the exploding weapons, the fuel used by the planes, the heat and pollution caused while manufacturing and transporting the weapons and the hardware, and by the energy needed to re-build and replace what was destroyed.

Progressing to the middle of the $20^{\text {th }}$ century there were about 125 'smaller' wars, some with 'large' players. Continuing from 1950 to-date, there were about 180 cases of war activity, some very significant, suggesting that more heat continued to be added to that which was produced during WW2.

At this point, reference is made to a graph produced by the Intergovernmental Panel on Climate Change, (IPCC), and reproduced in the book of Al Gore ' $A n$ Inconvenient Truth' on pages 72 and 73 [1]. The graph shows the 'temperature average' against time. It also shows the ordinates of recorded temperature. The temperature ordinates are more important than the average, and the excursions of the values of temperature shown by the ordinates, above the mean temperature, are of greater significance since they must show the temperature corresponding to specific events.

The IPCC graph shows, for the period 1900 to 1950 , a consistent increase in temperature, peaking during the WW2 years and remaining high up to 1950. There are two prominent increases towards the end of WW2, which coincide with intensified war activity, particularly the destruction of many cities, and with the heat released by the use of atomic weapons.

Variations in temperature show a distinct increase from the days of the Spanish Civil War and leading up to the start of WW2. The temperature shows a small decrease up to 1975 and then a distinct increase up to year 2005. The increase corresponds with the unabated war activity which has continued right up to 2005. From 1970 onwards the increase in the height of the ordinates follows the intensity of events such the Gulf War, Iran-Iraq War, the war activity in Southern Europe, the war in Afghanistan and the World Trade Centre incident which must have contributed significantly to the heat which was added to the planet's atmosphere.

According to the Gaia hypothesis 'the biosphere and the physical components of the earth are closely integrated to form a complex interacting system that maintains the climatic and biochemical conditions on earth, in a preferred 'homeorhesis'. Undoubtedly, and under the circumstances mentioned above, the following hypothesis can be added, that 'the planet's specification, which must have been used for its construction, does not allow for silly games'.

\section{Reference}

[1] Al Gore, An Inconvenient Truth, Melcher Media, Rodale 2006. 